\title{
Extended Access List untuk Mengendalikan Trafik Jaringan
}

\author{
Hari Antoni Musril ${ }^{\# 1}$ \\ \# Jurusan Pendidikan Teknik Informatika dan Komputer Fakultas Tarbiyah dan Ilmu Keguruan IAIN Bukittinggi \\ ${ }^{1}$ kum_ayik@yahoo.co.id
}

\begin{abstract}
Abstrak - Keamana jaringan komputer saat ini menjadi hal penting untuk diterapkan. Banyak organisasi yang telah menjadikan teknologi informasi sebagai bahagian penting dalam menunjang aktivitasnya. Akses pengguna yang tidak dibatasi menjadi ancaman bagi sebuah organisasi, karena banyak data dan informasi penting yang tersebar dalam perangkat jaringan komputer di organisasi tersebut dapat disusupi oleh pihak yang tidak berwenang. Salah satu usaha yang dapat dilakukan adalah dengan menerapkan extended access list yang merupakan salah satu bagian dari metode access control list. Extended access list dapat menyaring lalu lintas data suatu jaringan dengan mengontrol apakah paket-paket tersebut dilewatkan atau dihentikan. Extended access list juga dapat menjamin keamanan untuk setiap komputer sehingga jalur komunikasi serta hak akses setiap komputer dapat berjalan dengan baik. Extended access list memungkinkan penyaringan berdasarkan sumber atau alamat tujuan, protokol yang dipilih, port yang digunakan, dan apakah koneksi sudah ditetapkan. Tulisan ini membahas penerapan extended access list dalam jaringan supaya dapat melakukan filter terhadap paket data yang melewati jaringan. Penerapannya menggunakan software Packet Tracer 6.1.1 untuk membuat prototipe jaringan dan mensimulasikannya. Sehingga nanti dapat diterapkan pada jaringan yang sebenarnya. List yang dibangun pada penelitian ini diterapkan untuk protokol antara lain : TCP (WWW, FTP, Telnet, SMTP, POP3), UDP (DNS), dan ICMP (Ping). Hasilnya didapatkan extended access list yang dikonfigurasi pada router dalam topologi penelitian ini mampu melakukan filter terhadap paket yang melewati jaringan. Hasil konfigurasinya sangat spesifik, sehingga penerapan hak akses permit dan deny dapat dilakukan sesuai dengan aturan dan skenario yang dirancang.
\end{abstract}

Kata kunci-access control list, extended access list, router, protocol, network, paket data, filter.

\section{Pendahuluan}

Perkembangan teknologi informasi yang cukup pesat dewasa ini berimplikasi terhadap ancaman keamanan jaringan komputer. Hal tersebut dapat terjadi karena akses teknologi informasi sangat mudah dilakukan. Mudahnya akses ini seiring dengan berkembangnya teknologi internet. Hal tersebut tentunya perlu menjadi perhatian bagi sebuah organisasi dan institusi baik nilik swasta maupun milik pemerintah. Perlu diterapkan berbagai strategi untuk bisa menjamin keamanan data dan informasi dari pihak-pihak yang tidak berkepentingan. Akses dalam sebuah jaringan komputer harus diawasi dan dibatasi.

Salah satu upaya yang dapat dilakukan adalah dengan menerapkan access control list pada jaringan komputer. Access control list merupakan sebuah metode yang digunakan untuk menyeleksi paketpaket yang keluar masuk network [1]. Access control list adalah daftar aturan untuk mengizinkan atau menolak akses jaringan ke sebuah endpoint [2]. Penggunaan access list yang paling umum digunakan adalah penyaringan paket yang tidak diinginkan ketika mengimplementasikan kebijakan keamanan [3]. Access list bekerja menyaring lalulintas data suatu network dengan mengontrol apakah paket-paket tersebut dilewatkan atau dihentikan pada alat penghubung (interface) router [4].

Extended access list merupakan salah satu jenis access control list yang sering dan banyak digunakan untuk mengatur keamana jaringan. Pengaturan menggunakan extended access list sangat spesifik, sehingga memudahkan administrator jaringan dalam mengatur trafik data di dalam jaringan.

\section{LANDASAN TEORI}

\section{A. Access Control List}

Access control list (ACL) berfungsi untuk mengizinkan atau membatasi paket data yang melintas pada sebuah jaringan. Access control list merupakan suatu metode yang mengatur lalu lintas IP pada pintu masuk jaringan dan memfilter paket data pada saat akan melewati router apakah akan diizinkan melalui router atau ditolak [4]. Jadi pengaturan ACL ini dilakukan di dalam router yang terdapat pada sebuah jaringan. Router menguji semua paket data untuk menentukan apakah paket tersebut diijinkan untuk lewat atau tidak berdasarkan kriteria yang ditentukan di dalam access list [4]. Router ACL membuat keputusan berdasarkan 
alamat asal, alamat tujuan, protokol, dan nomor port [5]

Access list dibagi atas dua kelompok, yaitu standard access list (1-99) dan extended access list (100-199) [6]. Standar access list dalam melakukan penyaringan paket data hanya memperhatikan alamat sumber (alamat asal) dari paket yang dikirimkan. Sedangkan extended access list mempertimbangkan antara lain adalah alamat sumber (pengirim) dan alamat tujuan (penerima) paket data, protokol dan jenis yang digunakan. Sehingga extended access list lebih spesifik dalam melakukan penyaringan paket data.

Mekanisme dasar ACL yakni menyaring paket yang tidak diinginkan ketika komunikasi data berlangsung sehingga menghindari permintaan akses maupun paket data yang mencurigakan dalam akses keamanan sebuah jaringan [7]. Apabila ditemukan akses yang tidak diizinkan maka router akan langsung memblok alamat perangkat jaringan tersebut. Saat router memutuskan apakah perlu mem-forward atau memblok sebuah paket, software cisco IOS mengetes paket tersebut untuk setiap statemen kriteria dalam urutan yang sesuai saat mereka dibuat [3].

\section{B. Extended Access List}

Extended access list memungkinkan penyaringan berdasarkan sumber atau alamat tujuan, protokol yang dipilih, port yang digunakan, dan apakah koneksi sudah ditetapkan [8]. Dengan menggunakan extended access list, kita dapat secara efektif mengizinkan akses pengguna ke LAN fisik dan menghentikan mereka dari mengakses host tertentu atau hanya layanan tertentu saja dari host tersebut [9].

Terdapat dua keadaan yang didefinisikan pada pengaturan list tersebut, yaitu permit dan deny. Perintah untuk mengkonfigurasi extended access list secara umum dapat digambarkan seperti gambar 1 berikut ini [10] :

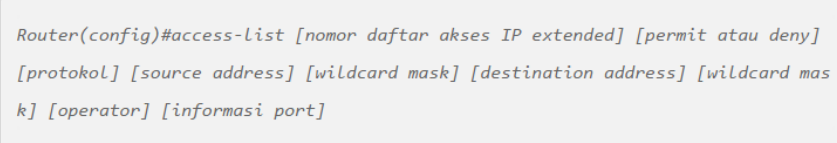

Gambar 1. Sintak konfigurasi extended access list

Nomor daftar akses IP extended adalah 100 hingga 199 [11]. Untuk protokol yang digunakan antara lain terdapat pada tabel I.
TABEL I

NAMA DAN NOMOR PORT PROTOKOL [12]

\begin{tabular}{|l|l|l|l|}
\hline $\begin{array}{l}\text { Jenis } \\
\text { Protokol }\end{array}$ & $\begin{array}{l}\text { Nama } \\
\text { Port }\end{array}$ & $\begin{array}{l}\text { Informasi } \\
\text { Port }\end{array}$ & $\begin{array}{l}\text { Nomor } \\
\text { Port }\end{array}$ \\
\hline \multirow{4}{*}{ TCP } & FTP Data & ftp-data & 20 \\
\cline { 2 - 4 } & FTP Control & ftp & 21 \\
\cline { 2 - 4 } & Telnet & telnet & 23 \\
\cline { 2 - 4 } & SMTP & smtp & 25 \\
\cline { 2 - 4 } & WWW & www & 80 \\
\hline \multirow{4}{*}{ UDP } & DNS Query & dns & 53 \\
\cline { 2 - 4 } & TFTP & tftp & 69 \\
\cline { 2 - 4 } & SNMP & snmp & 161 \\
\cline { 2 - 4 } & IP RIP & rip & 520 \\
\hline
\end{tabular}

Kesalahan pada saat pengaturan list dapat membuat jaringan menjadi down. Untuk itu diperlukan kecermatan administrator jaringan dalam melakukan analisis sebelum membuatkan list di router. Pengaturan dapat dilakukan untuk tiga keadaan, yaitu network ke network, host ke network, dan host ke host.

\section{Metode Penelitian}

Pada tulisan ini metode penelitian yang digunakan adalah :

1. Analisis (Analysis). Pada tahapan ini dilakukan analisis literatur yang relevan. Literatur bersumber dari buku, jurnal ilmiah, dan penelitian yang membahas mengenai extended access list.

2. Desain (Desaign). Tahapan desain berisikan bentuk prototipe topologi jaringan yang dikembangkan. Desain ini meliputi skenario jaringan secara fisik dan juga logika. Perancangan prototipe jaringan memanfaatkan software simulasi jaringan komputer Cisco Packet Tracer 6.1.1.

3. Pengembangan (Development). Tahapan ini dilakukan untuk mengkonfigurasi prototipe jaringan yang telah didesain sebelumnya. Konfigurasi dilakukan pada setiap device yang ada di dalam prototipe jaringan, antara lain adalah PC, laptop, server, dan router. Konfigurasi extended access list dilakukan di router dengan mengetikkan kode program pada jendela CLI router tersebut. Pengaturan router dilakukan untuk pengendalian trafik jaringan sehingga bisa melakukan penyaringan paket data dalam jaringan. 
4. Pengujian (Test). Setelah prototipe jaringan selesai dikembangkan, setiap device dilakukan pengujian konektivitasnya. Extended access list yang telah dibuat harus dapat berjalan di dalam prototipe jaringan ini. Apabila tidak berhasil, maka kembali dilakukan tahapan konfigurasi (pengembangan) sampai pengujian sukses dilakukan.

\section{PEMBAHASAN}

\section{A. Topologi Jaringan untuk Penelitian}

Topologi jaringan yang digunakan dalam penelitian ini adalah seperti gambar 2 berikut ini.

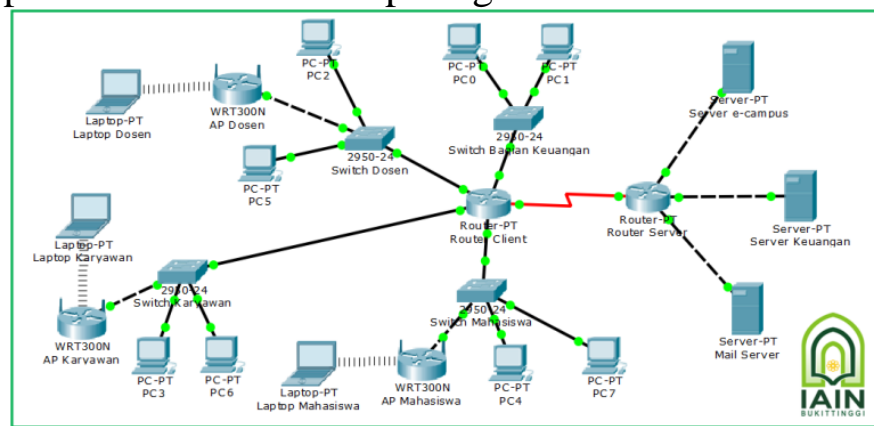

Gambar 2. Topologi jaringan yang digunakan dalam penelitian

Berdasarkan topologi di atas, dapat diatur pengalamatan setiap device seperti pada Tabel II.

Setiap device dikonfigurasi sesuai dengan alamat yang ada pada tabel di atas. Kemudian dilakukan pemeriksaan apakah setiap komponen jaringan telah terhubung atau belum.

\section{B. Pengaturan Alamat Router}

Langkah selanjutnya adalah melakukan proses routing pada router server dan router client sehingga kedua router dapat saling berkomunikasi. Routing protocol yang digunakan adalah RIPv2. Berikut ini adalah pengaturannya pada jendela CLI masingmasing router.

Konfigurasi di router server :

Router>enable

Router\#configure terminal

Router(config) \#hostname Router Server

Router Server(config) \#router rip

Router Server(config-router) \#version 2

Router Server(config-router) \#network 192.168.0.0

Router_Server(config-router) \#network 118.97.170.0

Router Server(config-router) \#network 10.121.45.0

Router Server(config-router) \#network 188.125.173.0

Router_Server(config-router) \#no auto-summary

Router Server(config-router) \#exit
TABEL II

Pengaturan Alamat DEVICE Jaringan

\begin{tabular}{|c|c|c|}
\hline $\begin{array}{l}\text { Nama } \\
\text { Perangkat }\end{array}$ & IP Address /Prefix & $\begin{array}{l}\text { Default } \\
\text { Gateway }\end{array}$ \\
\hline $\begin{array}{l}\text { Router } \\
\text { Server }\end{array}$ & $\begin{array}{l}\mathrm{Fa} 0 / 0: 118.97 .170 .100 / 24 \\
\mathrm{Fa} 1 / 0: 10.121 .45 .100 / 24 \\
\mathrm{Fa} 8 / 0: 188.125 .173 .100 / 24 \\
\text { Serial } 2 / 0: 192.168 .0 .1 / 24\end{array}$ & - \\
\hline $\begin{array}{l}\text { Router } \\
\text { Client }\end{array}$ & $\begin{array}{l}\mathrm{Fa} 0 / 0: 193.169 .10 .100 / 24 \\
\mathrm{Fa} 1 / 0: 195.171 .10 .100 / 24 \\
\mathrm{Fa} 6 / 0: 197.173 .10 .100 / 24 \\
\mathrm{Fa} 7 / 0: 199.175 .10 .100 / 24 \\
\text { Serial2/0 : 192.168.0.2 /24 }\end{array}$ & - \\
\hline $\begin{array}{l}\text { Server e- } \\
\text { campus }\end{array}$ & 118.97.170.198/24 & $118.97 .170 .100 / 24$ \\
\hline $\begin{array}{l}\text { Server } \\
\text { Keuangan }\end{array}$ & $10.121 .45 .152 / 24$ & $10.121 .45 .100 / 24$ \\
\hline Mail Server & $188.125 .173 .108 / 24$ & $188.125 .173 .100 / 24$ \\
\hline $\begin{array}{l}\mathrm{PC} \\
\text { Keuangan }\end{array}$ & $\begin{array}{l}193.169 .10 .1 / 24 \\
193.169 .10 .2 / 24\end{array}$ & $193.169 .10 .100 / 24$ \\
\hline PC Dosen & $\begin{array}{l}195.171 .10 .1 / 24 \\
195.171 .10 .2 / 24\end{array}$ & 195.171.10.100/24 \\
\hline $\begin{array}{l}\text { Laptop } \\
\text { Dosen }\end{array}$ & DHCP & 195.171.10.3/24 \\
\hline $\begin{array}{l}\mathrm{PC} \\
\text { Karyawan }\end{array}$ & $\begin{array}{l}197.173 .10 .1 / 24 \\
197.173 .10 .2 / 24\end{array}$ & $197.173 .10 .100 / 24$ \\
\hline $\begin{array}{l}\text { Laptop } \\
\text { Karyawan }\end{array}$ & DHCP & 197.173.10.3/24 \\
\hline $\begin{array}{l}\text { PC } \\
\text { Mahasiswa }\end{array}$ & $\begin{array}{l}199.175 .10 .1 / 24 \\
199.175 .10 .2 / 24\end{array}$ & $199.175 .10 .100 / 24$ \\
\hline $\begin{array}{l}\text { Laptop } \\
\text { Mahasiswa }\end{array}$ & DHCP & $199.175 .10 .3 / 24$ \\
\hline
\end{tabular}

Konfigurasi di router client :

\section{Router>enable}

Router\#configure terminal

Router(config) \#hostname Router Client

Router Client(config) \#router rip

Router Client (config-router) \#version 2

Router_Client (config-router) \#network 192.168.0.0

Router Client (config-router) \#network 193.169.10.0

Router_Client(config-router) \#network 195.171.10.0

Router Client (config-router) \#network 197.173.10.0

Router Client (config-router) \#network 199.175.10.0

Router_Client (config-router) \#no auto-summary

Router-Client (config-router) \#exit

\section{Konfigurasi Extendeed Access List}

Berikut adalah pengaturan dan skenario extended access list yang diterapkan pada topologi pada penelitian ini.

1. Server e-campus bisa diakses oleh dosen, bagian keuangan, karyawan, dan mahasiswa. Dengan demikian pada skenario ini tidak dibutuhkan pengaturan extended access list.

2. Server Keuangan hanya bisa diakses oleh bagian keuangan. Dosen, karyawan, dan mahasiswa 
masih tidak bisa mengakses server keuangan. Protocol pada server keuangan yang dikonfigurasi adalah HTTP, ICMP (ping), dan FTP. Pengaturan list extended dilakukan di router server. Berikut konfigurasi extended access list untuk memblok akses ke server keuangan :

a) Hanya komputer bagian keuangan yang bisa mengakses HTTP pada server keuangan. Konfigurasi pada bagian CLI di router server adalah seperti berikut ini.

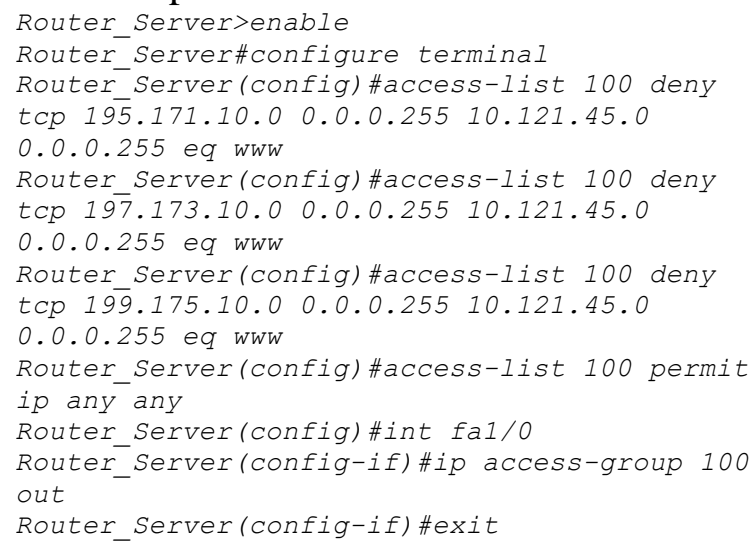

Daftar list extended yang dihasilkan adalah seperti gambar 3 di bawah ini.

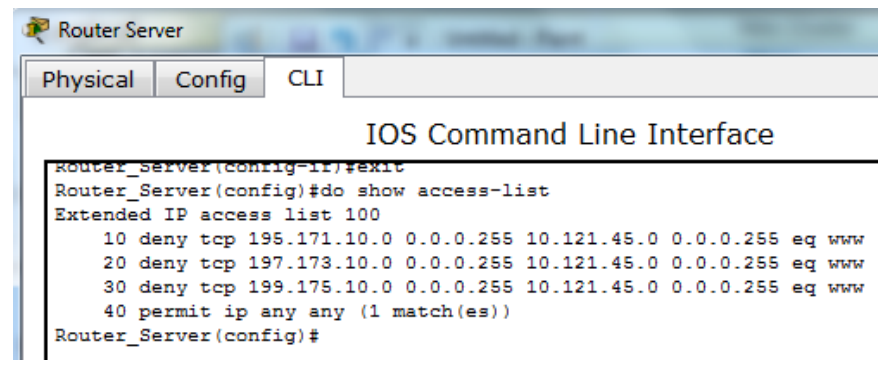

Gambar 3. Daftar list extended

Hasil yang didapatkan adalah komputer dan laptop yang ada pada bagian dosen, keuangan, karyawan, dan mahasiswa dapat merespon pesan ping, seperti gambar 4 berikut ini.

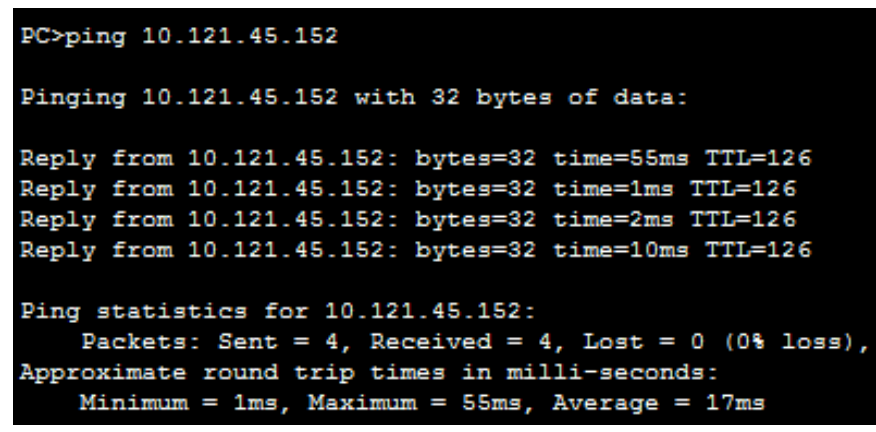

Gambar 4. Hasil uji ping ke server keuangan

Sedangakan untuk akses protokol http didapatkan hasil bahwa perangkat yang berada di daerah dosen, karyawan, dan mahasiswa tidak dapat mengakses web (www) yang ada pada server keuangan. Berikut ini tampilan pada browser komputer dosen, karyawan, dan mahasiswa.

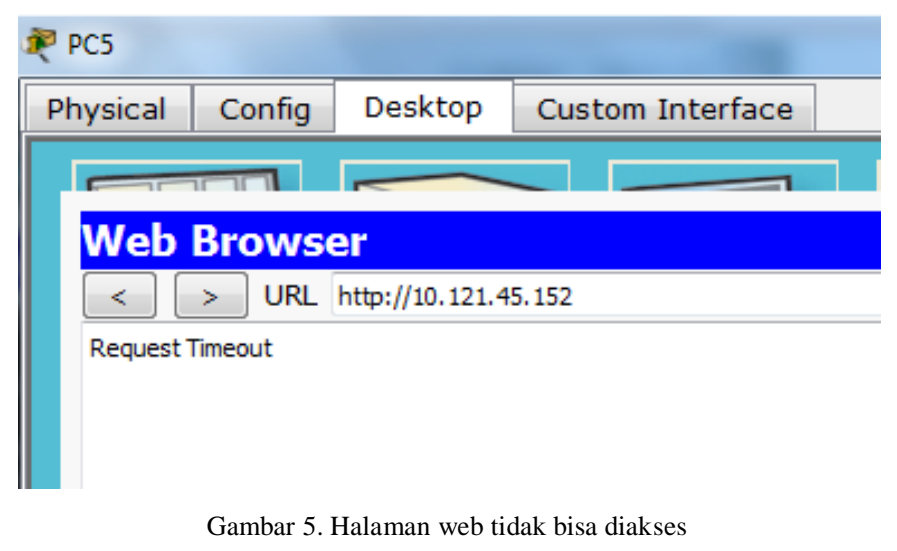

Komputer yang berada pada bagian keuangan dapat mengakses protokol http yang berada di server keuangan. Berikut ini tampilan pada browsernya.

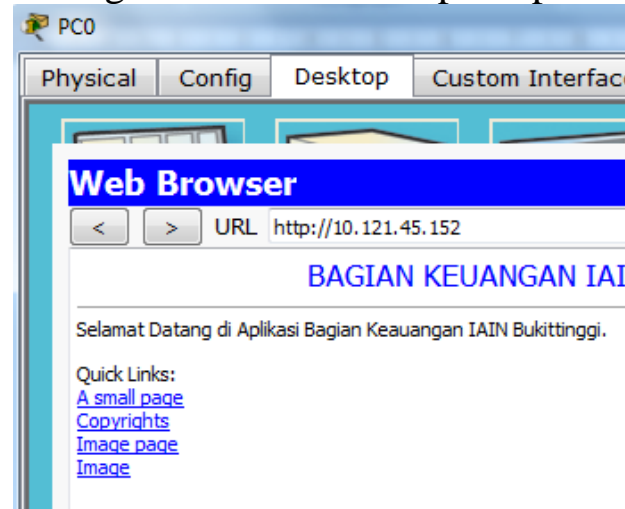

Gambar 6. Halaman web bisa diakses 
b) Melakukan blok terhadap protokol ICMP sehingga tidak dapat melakukan ping. Pengaturannya seperti berikut ini.

Router Server (config) \#access-list 101 deny icmp 195.171.10.0 0.0.0.255 10.121.45.0 0.0 .0 .255 echo

Router Server(config) \#access-list 101 deny icmp 195.171.10.0 0.0.0.255 10.121.45.0 0.0 .0 .255 echo-reply

Router Server(config) \#access-list 101 deny icmp 197.173.10.0 0.0.0.255 10.121.45.0 0.0 .0 .255 echo

Router Server(config) \#access-list 101 deny icmp $1997.173 .10 .0 \quad 0.0 .0 .25510 .121 .45 .0$ 0.0.0.255 echo-reply

Router Server(config) \#access-list 101 deny icmp 199.175.10.0 0.0.0.255 10.121.45.0 0.0 .0 .255 echo

Router_Server(config) \#access-list 101 deny icmp $199.175 .10 .0 \quad 0.0 .0 .25510 .121 .45 .0$

0.0 .0 .255 echo-reply

Router_Server(config) \#access-list 101 permit ip any any

Router Server(config) \#int fal/o

Router_Server(config-if) \#ip access-group 101 out

Router_Server(config-if) \#exit

Hasilnya didapatkan semua komputer dosen, karyawan, dan mahasiswa tidak sukses melakukan pesan ping. Sedangkan komputer bagian keuangan dapat melakukan pesan ping. Perhatikan gambar 7 berikut ini.

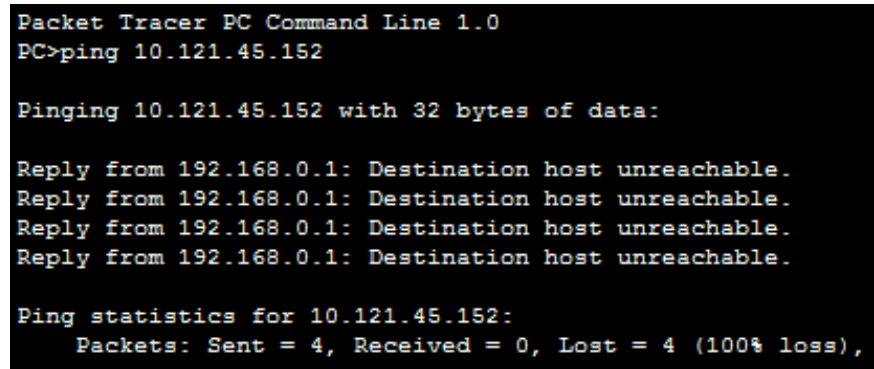

Gambar 7. Pesan ping gagal dilakukan ke server keuangan

c) Melakukan pembatasan terhadap protokol FTP. Konfigurasinya adalah seperti berikut ini.

Router Server(config) \#access-list 102 deny tcp 195.171.10.0 0.0.0.255 10.121.45.0 $0.0 .0 .255 \mathrm{eq}$ ftp

Router Server(config) \#access-list 102 deny tcp $19 \overline{7} .173 .10 .0 \quad 0.0 .0 .25510 .121 .45 .0$ $0.0 .0 .255 \mathrm{eq}$ ftp

Router Server(config) \#access-list 102 deny tcp 199.175.10.0 0.0.0.255 10.121.45.0 0.0 .0 .255 eq ftp

Router Server(config) \#access-list 102 permit ip any any

Router Server(config) \#int fal/0

Router_Server(config-if) \#ip access-group 102 out

Router_Server(config-if) \#exit
Router_Server(config) \#

Hasil yang didapatkan untuk bagian kepegawaian adalah seperti gambar 8 berikut ini.

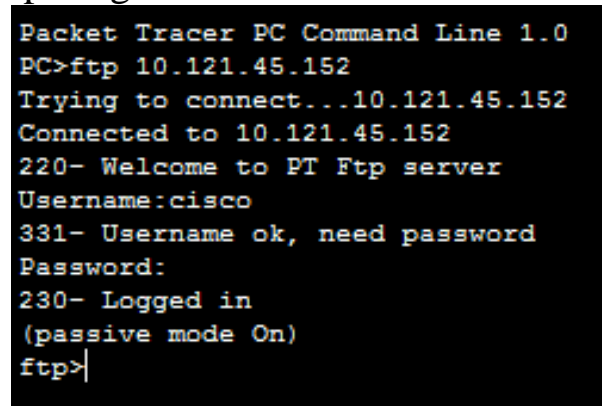

Gambar 8. Koneksi FTP berhasil

Sedangkan pada komputer dosen, karyawan, dan mahasiswa tidak dapat mengakses ftp. Perhatikan gambar 9 berikut ini.

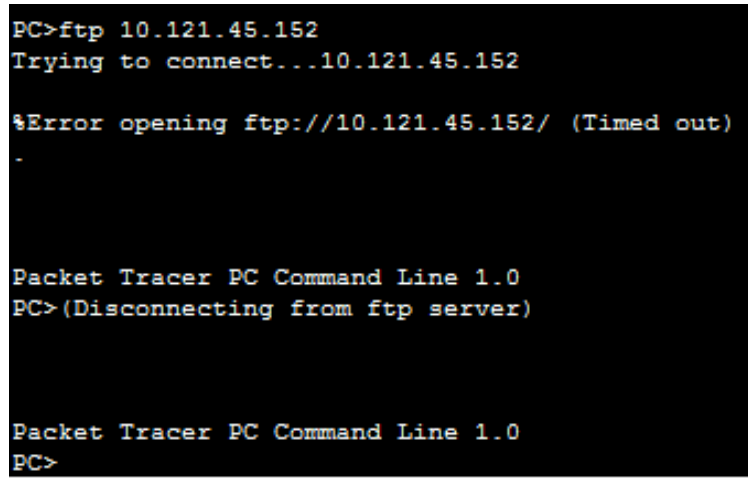

Gambar 9. Koneksi FTP tidak berhasil

3. Mail Server bisa diakses oleh dosen, bagian keuangan, dan karyawan. Sedangkan mahasiswa tidak dapat mengaksesnya. Pada bagian ini protokol yang dikonfigurasi adalah SMTP, POP3, dan DNS. Berikut pengaturannya :

a) Konfigurasi protocol SMTP dilakukan pada jendela IOS router server sebagai berikut. Router_Server(config) \#access-list 103 deñy tcp 199.175.10.0 0.0.0.255 $188.125 .173 .0 \quad 0.0 .0 .255 \mathrm{eq}$ smtp Router_Server(config) \#access-list 103 permit ip any any

Router Server(config) \#int fa8/0 Router Server(config-if) \#ip accessgroup $\overline{1} 03$ out

Router Server(config-if) \#exit Router_Server(config) \#

Setelah dilakukan konfigurasi didapatkan hasil komputer mahasiswa tidak dapat mengirimkan 
pesan (mail) karena tidak diizinkan mengakses mail server, namun komputer mahasiswa ini masih bisa menerima mail dari user lainnya karena protokol POP3 belum diblokir. Sedangkan komputer dosen, bagian keuangan, dan karyawan dapat terhubung ke mail server sehingga bisa mengirim dan membalas mail. Perhatikan gambar 10 dan 11 berikut ini.

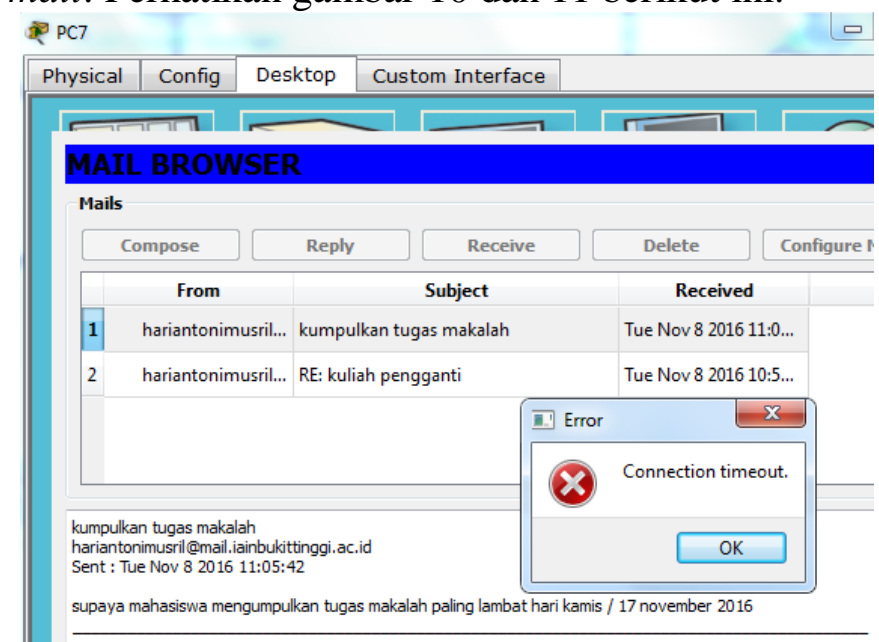

Gambar 10. Komputer mahasiswa tidak dapat mengirim mail, namun masih bisa menerima mail dari user lain

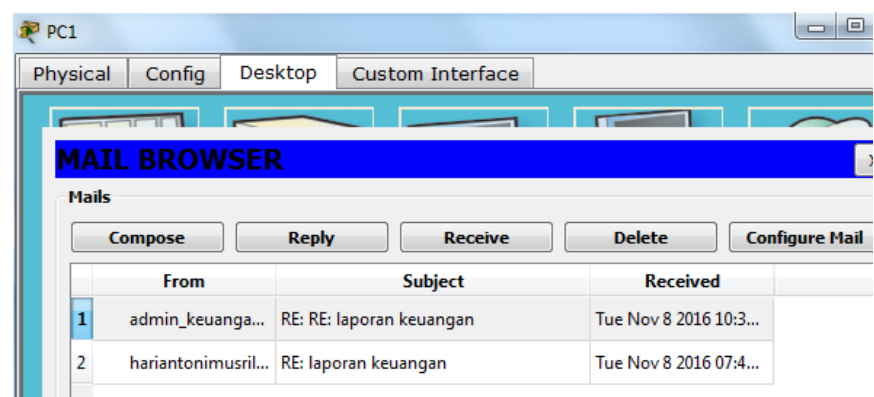

Gambar 11. Komputer dosen, bagian keuangan, dan karyawan bisa mengirim dan membalas mail

b) Pengaturan protokol POP3 dilakukan dengan perintah berikut ini.

Router_Server(config) \#access-list 104 deny tcp 199.175.10.0 0.0.0.255 188.125.173.0 0.0 .0 .255 eq pop3

Router_Server(config) \#access-list 104 permit ip any any

Router Server(config) \#int fa8/0

Router_Server(config-if) \#ip access-group 104 out

Router Server(config-if) \#exit

Router Server(config) \#

Hasilnya adalah komputer mahasiswa tidak dapat lagi menerima mail yang dikirimkan dari user lainnya. Tampilannya seperti gambar 12 .

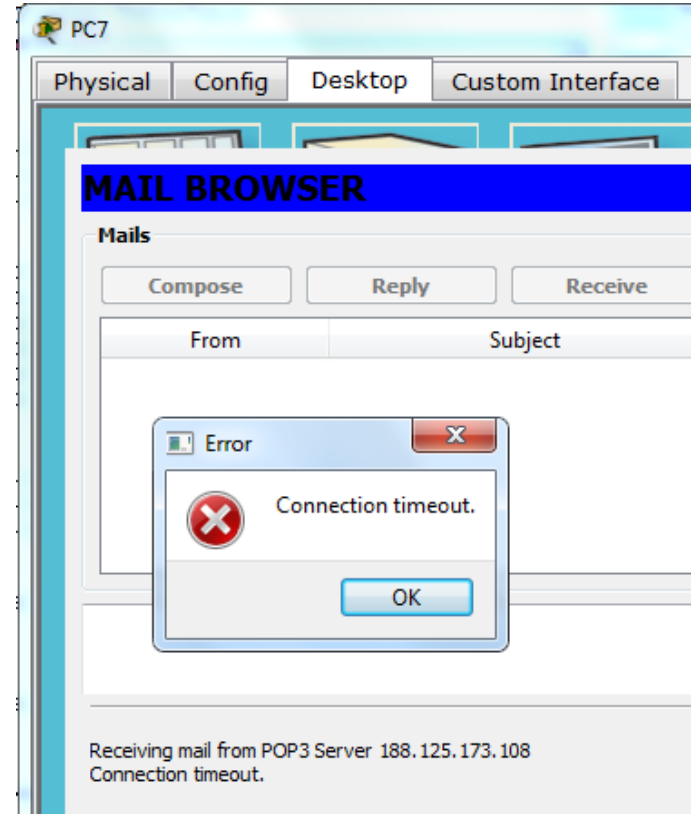

Gambar 12. Komputer mahasiswa tidak dapat menerima mail

c) Konfigurasi DNS dapat dilakukan dengan perintah berikut ini.

Router_Server(config) \#access-list 105 deny udp 199.175.10.0 0.0.0.255 188.125.173.0 0.0 .0 .255 eq domain

Router_Server(config) \#access-list 105 permit ip any any

Router Server(config) \#int fa8/0

Router Server(config-if) \#ip access-group 105 out

Router_Server(config-if) \#exit

Router Server(config) \#

Hasil dari pengaturan ini adalah komputer mahasiswa tidak dapat membuka domain name yang ada di mail server. Sedangkan komputer dosen, bagian keuangan, dan karyawan dapat membuka domain tersebut. Perhatikan gambar 13 dan 14 berikut ini.

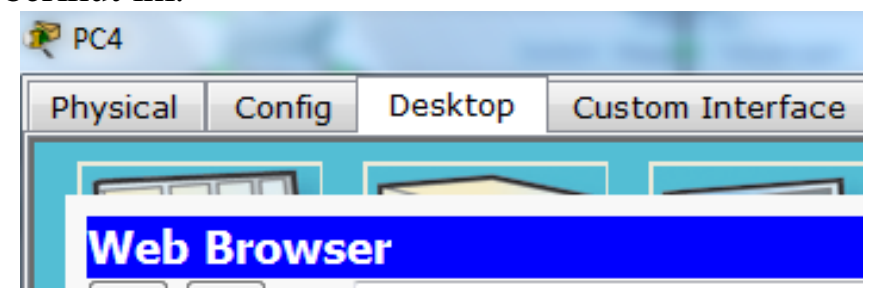

$<>$ URL http://www.sia.iainbukittinggi.ac.id

Host Name Unresolved

Gambar 13. Komputer mahasiswa tidak dapat membuka domain name 


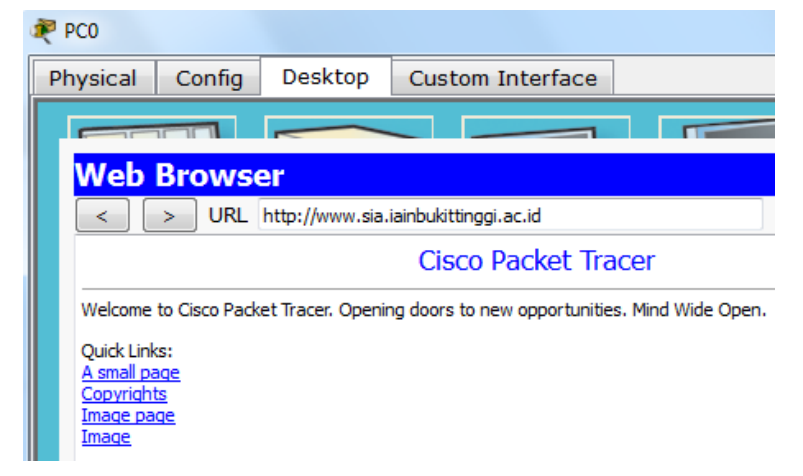

Gambar 14. Komputer dosen, bagian keuangan, dan karyawan dapat membuka domain name

d) Konfigurasi telnet dilakukan seperti berikut. Mengaktifkan telnet di router server dilakukan dengan mengetikkan perintah berikut di CLI router server.

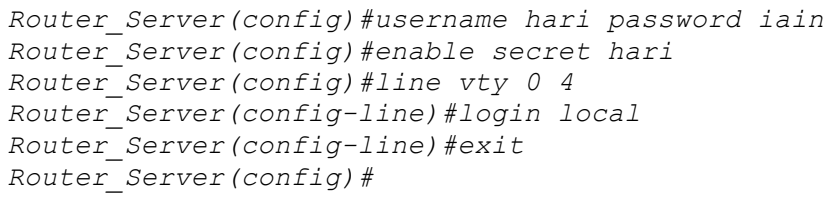

Berikutnya dilakukan skenario dimana komputer mahasiswa tidak bisa mengakses telnet di router server. Berikut ini adalah konfigurasinya.

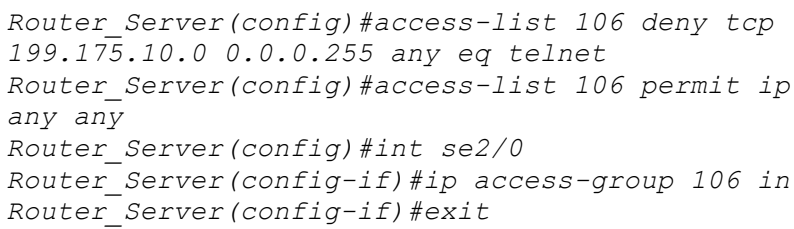

Didapatkan hasil bahwa komputer yang ada di bagian mahasiswa tidak dapat menjalankan telnet. Sedangkan komputer dosen, bagian keuangan, dan karyawan dapat melakukan telnet. Perhatikan gambar berikut ini.

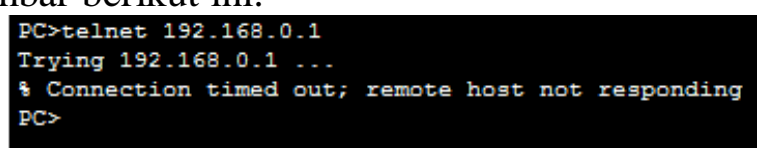

Gambar 15. Komputer mahasiswa tidak bisa mengakses telnet

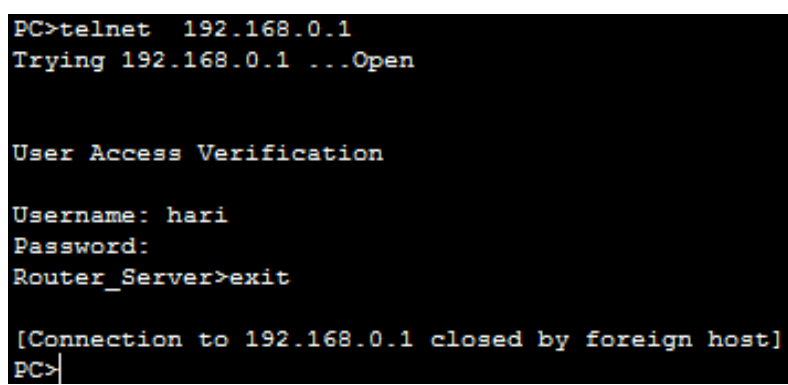

Gambar 16. Komputer dosen, bagian keuangan, dan karyawan dapat mengakses telnet

\section{KESIMPULAN}

Berdasarkan pada percobaan yang telah dilakukan, extended access list dapat melakukan pengendalian trafik jaringan dengan menyaringan paket data yang melewati router. Router akan melakukan pengecekan access list pada saat setiap paket data akan masuk pada port yang ada di router tersebut. Extended access list melakukan pengecekan terhadap beberapa atribut, yaitu alamat sumber, alamat tujuan, protokol, dan nama port. Pada penelitian ini protokol yang dikonfigurasi antaralain adalah TCP (port yang diatur adalah www/http, telnet, ftp, dan smtp), UDP (port yang diatur adalah dns), dan ICMP (port yang dikonfigurasi adalah ping). Hasil dari pengaturan terhadap semua port tersebut adalah sesuai dengan konsep dan skenario yang direncanakan dalam penelitin. Sehingga dapat disimpulkan bahwa extended access list melakukan filter terhadap trafik jaringan dengan sangat spesifik sehingga mampu memberikan jaminan terhadap keamana dalam sebuah jaringan.

\section{REFERENSI}

[1] Sofana, Iwan. 2012. Cisco CCNA \& Jaringan Komputer. Bandung : Informatika.

[2] Washam, M., Rainey, R. 2015. Exam Ref 70-533 Implementing Microsoft Azure Infrastructure Solutions. Washington : Microsoft Press.

[3] Purwanto, Agus D., Badrul, Muhammad. 2016. Implementasi Access List Sebagai Filter Traffic Jaringan (Study Kasus PT. Usaha Entertainment Indonesia). Jakarta, Jurnal Teknik Komputer AMIK BSI Vol 2 No 1

[4] Rahmawati. 2015. Konfigurasi Keamanan Jaringan Komputer Pada Router Dengan Metode ACL'S. Jakarta, Jurnal Teknik Komputer AMIK BSI Vol 1 No 2

[5] Dinata, Septian Krisna. 2013. Monitoring Aktifitas Jaringan dan Simulasi Access Control List Pada STMIK PalComTech Berbasis Cisco Router. Palembang, Jurnal Teknologi dan Informatika (TEKNOMATIKA) Vol 3 No 1.

[6] Saputro, Joko. 2010. Praktikum CCNA di Komputer Sendir Menggunakan GNS3. Jakarta : MediaKita.

[7] Rafiudin, Rahmat. 2008. SQUID. Yogyakarta : Andi Offset.

[8] Mason, Andrew G., Newcomb, Mark J. 2001. Cisco Secure Internet Security Solutions. Indianapolis : Cisco Press.

[9] Lammle, Todd. 2005. CCNA First Pass 2nd Edition. New Jersey : Wiley Publishing, Inc.

[10] Lee, Donald C. 2002. Enhanced IP Services for Cisco Networks. Indianapolis : Cisco Press.

[11] Rafiudin, Rahmat. 2004. Mengupas Tuntas Cisco Router. Jakarta : Elex Media Komputindo.

[12] Suman, S., Agrawal, ER. Aditi. 2016. IP Traffic Management With Access Control List Using Cisco Packet Tracer. India, International Journal of Science, Engineering and Technology Research (IJSETR) Vol 5 No 5 . 